\title{
Children, Value of
}

Elizabeth Thomson, Stockholm University, Stockholm, Sweden; and University of Wisconsin-Madison, Madison, WI, USA

(c) 2015 Elsevier Ltd. All rights reserved.

\begin{abstract}
In demography, the value of children refers most often to the benefits parents receive from having and rearing children. Benefits may accrue from the children themselves, from the experience of rearing them, or from the responses of kin, community, and society at large. Children also entail costs for parents and the value of children sometimes refers to their net value (benefits less costs). Benefits and costs of children are shaped by the economic conditions of life, forms of social organization, and cultural beliefs and practices. Studies using surveys to measure the value of children report variation in values across societies; by socioeconomic status; between women and men; for first, second, and higher order births; and for daughters versus sons. Cultural foundations for the value of children have also been explored. The net value of children underlies parents' desires for children which, in combination with their ability to achieve those desires, influences their decisions to have children and how many children they have.
\end{abstract}

\section{Theoretical Development}

Theories of fertility decline focus primarily on the economic value of children. In agricultural economies and during early periods of industrialization, parents and kin make the heavy investment of time and money in young children in order to reap the rewards of children's labor from adolescence onward (Schultz, 1973; Caldwell, 1976). The old-age security value of children is particularly important in contexts where no public provisions exist for elder care (Cain, 1985). For large numbers of people throughout the world, the economic value of children in the intermediate and long term continues to be a primary benefit of parenthood (Nauck and Klaus, 2007). Even in wealthy societies where children's labor is no longer central to their parents' subsistence, adult children may remain important to the economic well-being of elderly parents (Rendall and Bahchieva, 1998; Buehler, 2008).

Scholars have long recognized that the value of children extends beyond their direct economic benefits. The term 'value of children' is most closely associated with Hoffman and Hoffman (1973), who identified nine psychological needs fulfilled by parenthood and the experience of child-rearing: (1) adult status and social identity; (2) expansion of the self; (3) morality; (4) primary group ties, affiliation; (5) stimulation, novelty, fun; (6) creativity, accomplishment, competence; (7) power, influence, effectance; and (8) social comparison, competition. Most of these psychological needs have an inherently social character, an issue that becomes clear in subsequent theory and research.

Several scholars have attempted to develop a unifying theory of the value of children. Friedman et al. (1994) claim that the primary value of children is the reduction of uncertainty. Those with limited access to other means for uncertainty reduction, such as stable careers and marriages, will want to become parents. Few of the hypotheses derived from this theory stand up to empirical scrutiny, however, and those that do can be explained by the economic and social opportunity costs of children (Lehrer et al., 1996).

Building on the work of cultural anthropologists and sociologists, Schoen et al. (1997) propose that children produce social capital, i.e., social relationships and social resources. At birth, children strengthen parents' ties to kin. Through schooling and other activities, they link parents with community resources. As adolescents and young adults, children bring new information, ideas, and social relationships to parental households. And most parents eventually obtain in-laws and grandchildren as a consequence of parenthood. Although the social capital argument was developed in the context where children have low or no economic value, it may have more general applicability. Where family, kin, and community ties provide economic opportunities and security, the social capital produced by children may be as economically valuable as their labor or accumulated wealth. Buehler (2008) makes a similar argument that parenthood is motivated by what he terms the 'structural value' of children, i.e., the expansion of personal networks and exchange relationships arising from the birth of a child. These networks and relationships produce in turn psychological rewards (Hoffman and Hoffman, 1973) and social capital (Schoen et al., 1997). But the extent to which the personal networks and exchange relationships are activated for the parents' well-being depends on the quality of the parentchild relationship.

Nauck (2007) derives the value of children from a general theory of social production functions in which individuals seek to maximize physical well-being and social esteem. Physical well-being requires comfort and stimulation; social esteem requires status, affect, and behavioral confirmation. The value of children is based on the extent to which children enable parents to achieve these five intermediate goals. The nature of the parent-child relationship means that stimulation, affect, and behavioral confirmation are confounded. The theoretically derived value of children is thus organized along lines identified by others - economic (comfort), social (status), and psychological (stimulation, affect, behavioral confirmation)

Children are also quite costly to their parents during the child-rearing years. Fertility declines in the twentieth century have been attributed in large part to declines in the economic value and increases in the economic costs of children to their parents (e.g., Caldwell, 1976). Most theorists distinguish 
between the direct costs of children (food, clothing, shelter, education, etc.) and the opportunity costs of childcare for the parents' alternative activities (Fawcett, 1978). Parents also incur social and psychological costs from their responsibilities for and interactions with children (Hoffman and Hoffman, 1973; Fawcett, 1978; Schoen et al., 1997; Buehler, 2008).

\section{Measuring the Value of Children}

The Value of Children (VOC) surveys conducted in the mid1970s (Fawcett, 1983) were based on the social psychological values developed by Hoffman and Hoffman (1973), but also contained information on the perceived economic benefits as well as the psychological, social, and economic costs of children. Respondents were asked open-ended questions about reasons for having or not having children and were asked to rate the importance of several lists of child benefits and costs as reasons to have or not have children or their next child. Most subsequent empirical research was based on closed-format questions. A partial replication of the VOC in the early 2000s (Nauck and Klaus, 2007) extended the importance scale from three to five points, improving the measures' reliability and validity. Seven-point importance ratings were used in the U.S. National Survey of Families and Households (Seccombe, 1991).

Subjective-expected-utility or expectancy-value models (e.g., Davidson and Jaccard, 1975) specify child benefits and costs as the product of the likelihood that having a child will produce a given outcome and the value (positive or negative) of the outcome. Each perceived likelihood and value is measured on a scale with several response options. More recent research in this tradition attempts to measure the combination of value and likelihood with a single response, e.g., agreement with a statement about positive or negative outcomes (Billari et al., 2009; but see Liefbroer, 2005).

Measurement analyses of child benefits and costs generally confirm the theoretical clusters of economic, social, and psychological well-being (Schoen et al., 1997; Nauck and Klaus, 2007), or at least separate the economic from the social and psychological (Mayer and Trommsdorff, 2010). Perceived costs constitute a separate dimension (Nauck and Klaus, 2007; Billari et al., 2009). Benefits and costs of children may also be distinguished in relation to general theories of fertility and fertility change (Liefbroer, 2005).

The real as opposed to perceived economic benefits and costs of children can also be measured indirectly based on the value of children's labor and transfers to parents over the life course, expenditures related to child-rearing, and the value of parental time that might otherwise be spent on incomeproducing activities (e.g., Rosenzweig, 1978). DiPrete et al. (2003) used a combination of time-budget data, attitude data, and estimates of the effects of a birth on labor earnings and standard of living changes to compare the economic costs - direct and opportunity - of children in different countries. In the aggregate, costs were strongly associated with national fertility rates. Zelizer (1985) argued that in a context where children's net economic value is zero, monetary compensation for a child's death represents children's net socioemotional value.

\section{Variations in the Value of Children}

\section{The Value of First- and Later-Born Children}

The original Value of Children studies found that first-, second-, and higher order births are associated with distinct benefits and costs (Bulatao, 1981; Fawcett, 1983). The first child confers the status of parenthood, so that benefits associated with parenthood per se can be acquired by having only one child. Adult status, relationship stability, parent-child interaction, and kin connections are all cited as primary reasons for becoming a parent. The first child is also associated with the greatest increase in opportunity costs, that is, constraints on parental time and energy.

The most important value of a second child is to provide a sibling for the first (Bulatao, 1981), a value that could be incorporated into the social dimension of child value discussed above. The value of higher order births may be predominantly economic - each child contributes additional labor or economic security for parents - but could also further strengthen partnership and kin ties and provide additional opportunities for rewarding parent-child interactions.

Griffith et al. (1985) pointed out that some of the unique values of first and second births may apply to the parity of a couple, independent of each partner's parity. She argued that the value of a child as a representation of the couple's commitment to one another would be relevant in stepfamilies, even when one or the other partner already had a child. The couple-specific value is argued to underlie the larger combined family sizes of step-family couples in comparison to couples in stable partnerships (Thomson, 2004).

Each child also adds to the parents' child-rearing costs, including direct financial expenditures and limitations on alternative uses of time. It appears, however, that cost considerations remain relatively stable across parities due to a trade off between quantity and quality (Bulatao, 1981; Nauck, 2007). That is, parents with small numbers of children may invest more time and money in each child than parents with larger numbers of children.

\section{Gender and the Value of Children}

Overall, men and women perceive the values and costs associated with children in much the same way. The few differences that are observed are consistent with traditional gender roles (Fawcett, 1983; Seccombe, 1991; Buehler, 2008). Liefbroer (2005) found that gender differences arose primarily from differential likelihood of outcomes for men and women, not the relative value of those outcomes. Men are, on average, more concerned than women about the financial costs of childrearing and in patrilineal societies about having sons to continue the family name. Women place greater importance than do men on the work and strain of raising children, and in some cases also the opportunity costs of children for other activities, and the benefits of children for the marital relationship (Fawcett, 1983).

Differences in the perceived benefits of daughters and sons are also related to differences in the roles and behaviors of men and women (Fawcett, 1983). In patrilineal societies, sons are valued more than daughters for kinship ties, that is, to continue the family name. Where men have greater access than women 
to economic opportunities, sons may also be valued for future financial assistance. Daughters are valued more than sons for household and childcare help and companionship. In patrilineal societies, the values associated with sons are produced for the most part in adulthood, those associated with daughters during childhood, consistent with the practice of daughters' leaving the parental home upon marriage. Many of the benefits of children, particularly social and psychological benefits, do not appear to differ for sons and daughters. Thus, where children provide few economic benefits, few parents express preferences for sons versus daughters, but rather prefer at least one of each (Hank, 2007).

\section{Socioeconomic Variation in the Value of Children}

As noted above, the economic value of children is associated with agricultural and household economic production and the absence of social insurance for elderly parents. Although children also entail high economic costs in such contexts, they are necessary for survival. Industrialization and urbanization reduce the economic value of child labor and increase the costs of rearing children to be economically independent. Economic development eventually leads to the development of social insurance that reduces further the economic value of children for support in old age. As a result, children's net economic value is perceived to be lower in industrialized wealthy countries than in poorer countries with a greater dependence on agricultural and household production (Fawcett, 1983; Nauck and Klaus, 2007), except for those at the bottom of the economic ladder in wealthy countries (Rendall and Bahchieva, 1998).

Psychological benefits and costs of children were reported in the original VOC surveys to be more important in industrial and postindustrial settings than in agricultural settings (Fawcett, 1983). This difference could arise because of the priority of economic survival over psychological well-being (Zelizer, 1985). Children may provide psychological benefits (and costs) for parents in all settings, but these components of child value become salient only when children become irrelevant to economic survival. The more recent VOC surveys find no difference across societies at different levels of economic development in the emotional value of children (Nauck and Klaus, 2007; Mayer and Trommsdorff, 2010).

Because the social capital or social esteem value of children has only recently been introduced into theoretical discussions of the value of children, it is difficult to know how such values might vary under different economic conditions. In agricultural settings, there may be a stronger association between economic and social ties so that the latter are not distinguishable from the former. Only in industrial and urban societies may social capital be sufficiently separable from financial capital to identify it as a separate source of child value.

Socioeconomic variation in the value of children is also evidenced across families within societies (Fawcett, 1983). A consistent finding from VOC surveys was that urban respondents place a lower economic value and a higher emotional value on children than do respondents living in rural areas. Similarly, education is inversely associated with children's economic value and directly associated with their emotional value as well as with perceived restrictions or opportunity costs of parenthood. Direct financial costs and childcare stresses do not vary substantially across countries or across individuals in different economic circumstances, likely due to the greater investments parents of higher socioeconomic status make in each child. Although one might expect the opportunity costs for mother's employment to increase with socioeconomic status, well-paid mothers can purchase substitute care. Klein and Eckhard (2007) found no differences in the perceived opportunity costs of children or in their effects on childbearing across socioeconomic levels.

\section{Culture and the Value of Children}

Broad cultural values may also serve as sources of specific or general values of children. Religious institutions and beliefs may support the value of children for social and psychological benefits. For example, Catholicism is viewed as a support for large-family values in the Philippines, Confucianism for the high value of sons to carry on the family name in some Asian countries. The relative values of daughters and sons are associated with broad cultural values on gender equality (Fawcett, 1983).

Lesthaeghe (1983) argues that ideational change is an independent force underlying current low fertility in Western countries. He identifies the two most salient features of this change as secularization and individuation. Secularization allows more latitude to individual morality; individuation stresses the importance of personal self-actualization. Using national surveys of social and family values, Lesthaeghe and colleagues (e.g., Lesthaeghe and Meekers, 1986) distinguish two dimensions of family values - a nonconformity dimension linked to partner relationships and nonmarital childbearing; and the 'meaning of parenthood,' including beliefs that children are necessary for fulfillment and for marital success. Measures of secularism and individuation were strongly associated with nonconforming family values, but only weakly associated with the meaning of parenthood.

This finding is consistent with the argument of Ehrhardt and Kohli (2011) who distinguish two dimensions of individualization. The first dimension, an increase in status of the individual - particularly children and women - underlies the decreased economic value and increased economic costs of children, including opportunity costs for their mother's employment. The second dimension, an increase in autonomy and freedom of choice, does not imply an increased competition between self-actualization and parenthood. It does underlie, however, dramatic decreases in union stability and the economic safety net for mothers and children, operating not through children's social and psychological benefits but through their economic costs.

\section{The Value of Children and Fertility}

Hoffman and Hoffman (1973) theorized that the influence of psychological needs met by parenthood or by particular numbers of children would depend on the intensity of such needs and the availability of alternative mechanisms for fulfilling them. Studies using ratings such as those in the VOC surveys have generally found that high perceived economic 
benefits of children are associated with a large family size. The importance of psychological benefits and restrictions on parental activities are associated with a small family size (Fawcett, 1983; Nauck, 2007; Mayer and Trommsdorff, 2010). The relationship between perceived child values and fertility is not, however, as strong as some scholars had hoped, and the financial and time/effort costs of children are not associated with family size (Fawcett, 1983; Nauck, 2007).

Relatively moderate associations between values of children and completed fertility should not be surprising. As noted above, many child values may be parity specific and should be expected to influence only specific parity progressions. Further, child values can influence only desired fertility, so that the relationship between values and outcomes depends on the degree of fertility control. In addition, early measures of the perceived value of children were relatively crude (e.g., threepoint response scale). When a particular parity progression is specified, when contraception is pervasive, and when precise measures of the expected value (net of cost) of children are generated, much stronger associations are observed between values and births (e.g., Liefbroer, 2005; Nauck, 2007).

Nauck (2007) argues further that fertility decision-making is likely to be rational - considering carefully the benefits and costs - primarily during a period of fertility transition. Before and after the transition, when most people share an understanding of children's values and costs, decision-making will be more routinized and spontaneous, thus more strongly influenced by prevailing social norms.

See also: Demographic Measurement: General Issues and

Measures of Fertility; Family Size Preferences; Family Theory:

Economics of Childbearing; Family Theory: Economics of

Intergenerational Relations; Fatherhood; Fertility Theory:

Theory of Intergenerational Wealth Flows; Fertility Transition:

Cultural Explanations; Fertility Transition: Economic

Explanations; Fertility and Social Networks; Second

Demographic Transition.

\section{Bibliography}

Billari, F.C., Philipov, D., Testa, M.R., 2009. Attitudes, norms and perceived behavioural control: explaining fertility intentions in Bulgaria. European Journal of Population 25, 439-465.

Buehler, C., 2008. On the structural value of children and its implication on intended fertility in Bulgaria. Demographic Research 18, 569-610.

Bulatao, R.A., 1981. Values and disvalues of children in successive childbearing decisions. Demography 18, 1-25.

Cain, M., 1985. Fertility as an adjustment to risk. In: Rossi, A.S. (Ed.), Gender and the Life Course. Aldine, New York, pp. 145-160.
Caldwell, J.C., 1976. Toward a restatement of the demographic transition theory. Population and Development Review 2, 321-366.

Davidson, A., Jaccard, J., 1975. Population psychology: a new look at an old problem. Journal of Personality and Social Psychology 31, 1073-1082.

DiPrete, T.A., Engelhard, H., Morgan, P., Pacalova, H., 2003. Do cross-national differences in the costs of children generate cross-national differences in fertility rates? Population Research and Policy Review 22, 439-477.

Ehrhardt, J., Kohli, M., 2011. Individualisation and fertility. Historical Social Research 36 (2), 35-64.

Fawcett, J.T., 1978. The value and cost of the first child. In: Miller, W.B., Newman, L.F. (Eds.), The First Child and Family Formation. Carolina Population Center, Chapel Hill, NC, pp. 244-265.

Fawcett, J.T., 1983. Perceptions of the value of children: satisfactions and costs. In: Bulatao, R.A., Lee, R.D. (Eds.), Determinants of Fertility in Developing Countries, Supply and Demand for Children, vol. 2. Academic Press, New York.

Friedman, D., Hechter, M., Kanazawa, S., 1994. A theory of the value of children. Demography 31, 375-401.

Griffith, J.D., Ko0, H.P., Suchindran, C.M., 1985. Childbearing and family in remarriage. Demography 22, 73-88.

Hank, K., 2007. Parental gender preferences and reproductive behaviour: a review of the recent literature. Journal of Biosocial Science 39, 759-767.

Hoffman, L.W., Hoffman, M.L., 1973. The value of children to parents. In: Fawcett, J.T. (Ed.), Psychological Perspectives on Population. Basic Books, New York, pp. 19-76.

Klein, T., Eckhard, J., 2007. Educational differences, value of children and fertility outcomes in Germany. Current Sociology 55, 505-525.

Lehrer, E.L., Grossbard-Shechtman, S., Leasure, J.W., 1996. A theory of the value of children - comment. Demography 33, 133-139.

Lesthaeghe, R., 1983. A century of demographic and cultural change in Western Europe: an exploration of underlying dimensions. Population and Development Review 9, 411-435.

Lesthaeghe, R., Meekers, D., 1986. Value changes and the dimensions of familism in the European Community. European Journal of Population 2, 225-268.

Liefbroer, A.C., 2005. The impact of perceived costs and rewards of childbearing on entry into parenthood: evidence from a panel study. European Journal of Population 21, 367-391.

Mayer, B., Trommsdorff, G., 2010. Adolescents' value of children and their intentions to have children: a cross-cultural and multilevel analysis. Journal of Cross-Cultural Psychology 41, 671-688.

Nauck, B., 2007. Value of children and the framing of fertility: results from a crosscultural comparative survey in 10 societies. European Sociological Review 23, 615-629.

Nauck, B., Klaus, D., 2007. The varying value of children: empirical results from eleven societies in Asia, Africa and Europe. Current Sociology 55, 487-503.

Rendall, M.S., Bahchieva, R.A., 1998. An old-age security motive for fertility in the United States? Population and Development Review 24, 293-307.

Rosenzweig, M.R., 1978. The value of children's time, family size and non-household child activities in a developing country: evidence from household data. In: Simon, J.L. (Ed.), Research in Population Economics: An Annual Compilation of Research, vol. 1, pp. 331-347.

Schoen, R., Kim, Y.J., Nathanson, C.A., Fields, J., Astone, N.M., 1997. Why do Americans want children? Population and Development Review 23, 333-358.

Schultz, T., 1973. The value of children: an economic perspective. Journal of Political Economy 81, S2-S13.

Seccombe, K., 1991. Assessing the costs and benefits of children: gender comparisons among childfree husbands and wives. Journal of Marriage and Family 53 , 191-202.

Thomson, E., 2004. Step-families and childbearing desires in Europe. Demographic Research, Special Collection 3, 117-134.

Zelizer, V., 1985. Pricing the Priceless Child: The Changing Social Value of Children. Johns Hopkins University Press, Baltimore, MD. 